\title{
Study on the transmission line bird
}

\author{
Dongfu Ma \\ North China Electric Power University (Baoding), Hebei, China \\ 2720247914@qq.com
}

Keywords: transmission line, bird mask, bird thorn, flashover

\begin{abstract}
In order to ensure the power supply reliability of transmission lines, reduce bird damage caused by the distribution of accidents, for the characteristics of birds, practical programmes, enhance the security of transmission line operation.
\end{abstract}

\section{Introduction}

With the deepening urban green development concept, people attach great importance to environmental protection, love Bird care bird growing awareness of citizens good improvement in living conditions of birds, bird populations and the considerable increase in the number ${ }^{[1]}$. With the development of the grid needs in many mountain regions, wetlands, also were included in the scope of construction, which makes the bird activity in the transmission line towers are also more frequent, including nesting in towers, activities above the insulators insulators, transmission line bird makes the regions have different degrees of incident. Therefore further research for characteristics of birds and propose practical solutions, for the safe operation of the grid and reduce economic losses have great practical significance. This paper analyses the characteristics of birds, combined with traditional measures of preventing bird, devised a new method of dealing with birds.

\section{Characteristics of the bird and the existing preventive measures}

\subsection{The specific factors of bird}

(1) Birds ' droppings flashover fault: in order to increase the Creepage distance, wire connection side hangs a lot of Poles and towers made of glass or ceramic plates made of insulators, insulator.When birds crossarm birds on the wire above the insulator when feces, bird droppings along the insulator lateral fall short cross arm with air gaps between the wires causing short. Or attached to the bird droppings on the insulator surface in moist environments, which gradually dissolved in water soluble, forming a layer of conductive film on insulator surface to make insulators insulation levels fell sharply, in the presence of electric fields strong discharge, causing the line to flashover. This phenomenon is similar to lightning strikes.

(2) Nest short-circuit fault: Some migratory birds, hawks, Magpies and other birds when nesting in transmission line Tower, its branches, straw, wire and other objects between wires or lines while flying, its object falls between the crossarm and wire, or when the wind and rain, the bird's nest were blown away or soaked, makes a charged wire or insulated grounding fault is raised.

(3) Bird flight failures: larger birds flying between the wires causing short circuit or single phase grounding fault this fault generally occurs only at $110 \mathrm{KV}$ and below line faults occur is very small.

\subsection{Characteristics to bird pest accident}

Birds congregate migratory habits, activities in space is relatively large, like alien in fixed locations, prowl during the day, nest at night. Birds of this behavior also makes the time distribution of bird-obviously, focus 10 o'clock at night until 8 o'clock the next day. Some trees more sparsely populated areas, transmission line towers ideal for Bird Habitat and stop and a place to rest, this makes the birds with a clear geographical distribution characteristics. 
Regional features of the distribution of birds

\begin{tabular}{|c|c|c|c|c|c|c|c|}
\hline distribution area & river & crop & forest & open area & the plains & marsh & other \\
\hline the incidence of (\%) & 38 & 17 & 12 & 9 & 16 & 4 & 6 \\
\hline
\end{tabular}

\subsection{Existing measures against birds}

Bird measures now can be roughly divided into two kinds, bird and block measures. Bird measures through the red flag hoisted on poles and towers, brush gorgeous paint, reflective windmills, installed speakers. Blocking measures to be installed on the crossarm some large bird bezel bird enclosures, bird nets, limit the bird's nest, where and so on.

\section{Bird-protection devices innovative research}

\subsection{A bird cross arm design}

Bird pest control often need to be combined in various ways. The Poles as shown in figure a, in rural areas, on the $10 \mathrm{KV}$ and $110 \mathrm{KV}$ transmission poles, birds nests occur, and the number continues to increase, this transmission had a tremendous security risk.

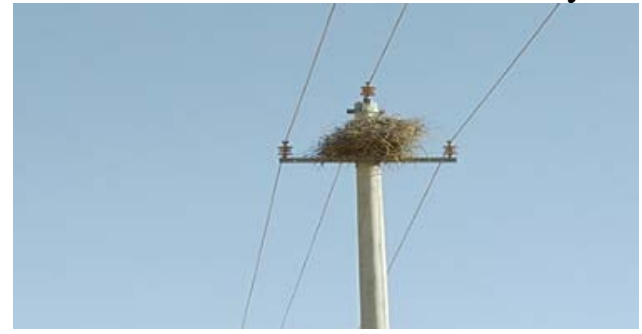

Figure 1

Combination of these cases devised a new cross arm as shown below:

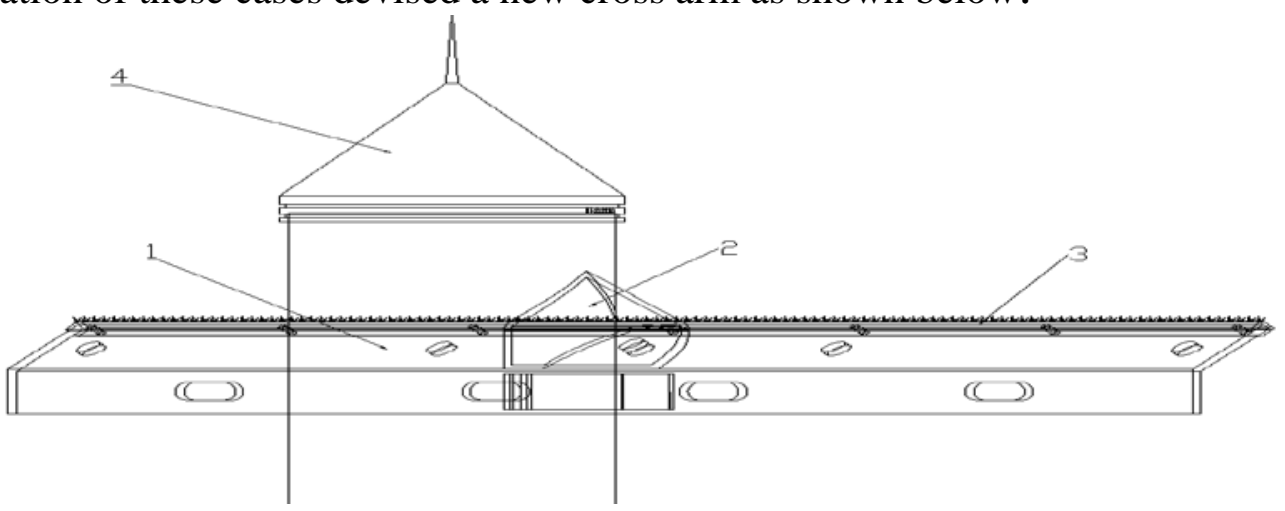

Figure 2

The cross arm angle two flat design is 135 degrees,and in its surface with reflective glass, installed a row of birds at the edge of the thorn 3, On which the birds cannot stay. In order to prevent birds in cross junction of TAM and poles to build nests, devised a bird mask 2 thread closely and fitting, to prevent the effects of bird nests. To prevent the birds ' droppings flashover, install bird pin in the insulator, effectively prevent the birds stay.

After experiments in pigeon shed found, unable to stop the pigeon in the cross arm, this great proves the feasibility of such a programme. The mechanical bird-proof measures, compared with other bird has became effective immediately upon installation, and ease of installation and operation, maintenance costs because of the low, and compared to other protective measures has the characteristic of low installation cost.

\section{2 based on infrared technology of sound-proof bird feeders}

Now most of the bird are almost all there is the question of the scope of protection of small, while for a large range of large bird-proof bezel, problems such as Assembly and disassembly. Especially for the case almost impossible to implement, as shown in the following figure III. It's from other methods are needed to solve. 


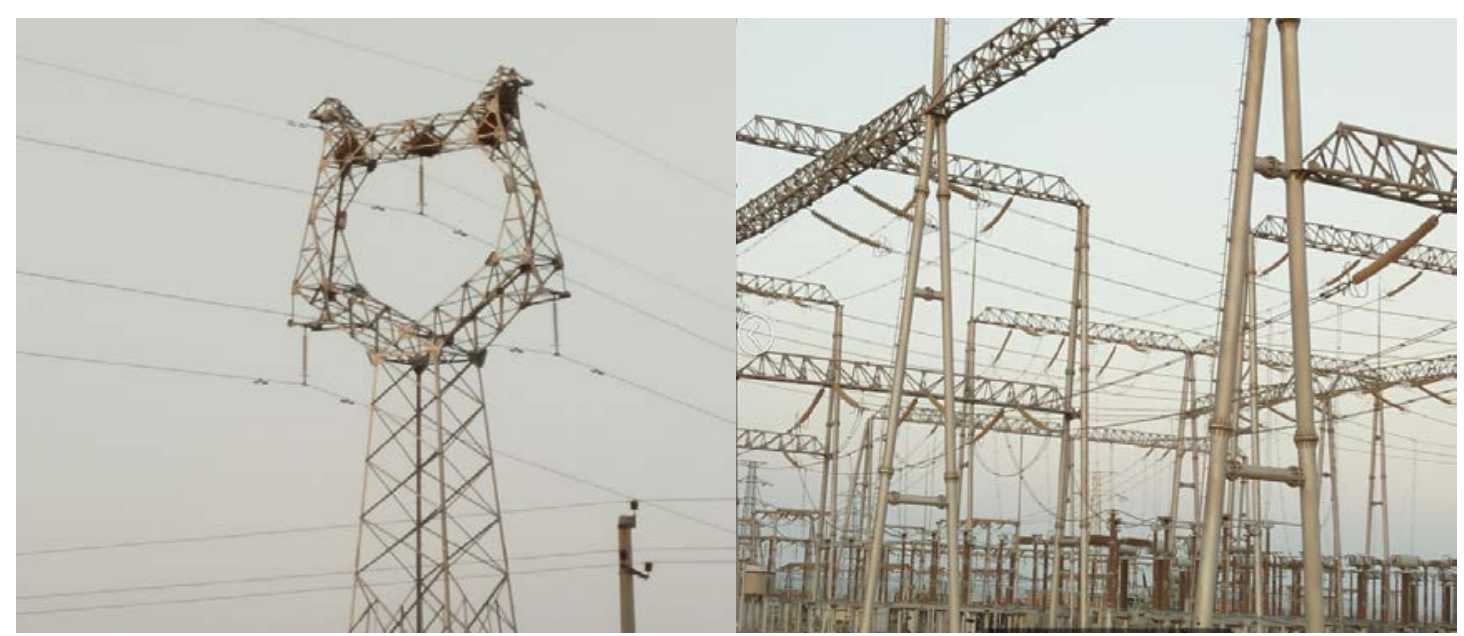

Figure 3

A sound device to prevent birds based on infrared sensor technology is to use infrared sensors to detect the heat around, when the birds flew around from the appliance, and give feedback to the controller sensor detects infrared signals, control Horn so as to achieve the effect of bird sounds made threats.

Bird is provided by solar power, with four infrared sensors to detect signals in all directions, controller programmed by single-chip microcomputer components. In order to avoid the birds in a certain period of time to adapt to the bird, and stored in the memory of several different threats sound, transform certain cycles.

Opens the existing bird repeller has been, it will not only cause great damage to power and noise affects the residents living around it. This device is only detected when the bird came back to sounding like dumb, so as to improve the shortcomings of the original product. And the device detection range for spherical area 2 metres in diameter, protected space. Due to small size, so it is very convenient to install and maintain. To a large extent, to solve bird pest problem in Figure III above.

\section{Summary}

Bird-proof measures and corresponding product has advantages and disadvantages for different occasions, should be combined with prevention in a different way. Notable is, birds so that our good friend, is a human construction which results in direct contradiction of these nature, so that in the future more when focusing on prevention and treatment of birds protection. The environment that we live in will be better.

\section{References}

[1] Ren Zengan. Zhu Shaomin. New type of bird hazard prevention cross arm [j]. rural electrification. 2014,01:56-57.

[2] Jia Leiliang. characteristics of birds ' droppings flashover on transmission line and countermeasure analysis [j]. electrical equipment. 2006,07:27-28.

[3] Mei Chao Mei, Pu Lu, Wang Xue, et al. analysis of overhead transmission line bird damage control techniques [j].Shanxi electric power 2008, 36 (8): 45-47.

[4] Xiong Chengrong. Transmission line bird damage control strategy of Jingzhou power supply company [j]. Hubei electric power 2010, 34 (4): 36-37.

[5] daixiaoguang, zhenwei Yang, Xie ping, et al. transmission line bird damage control strategy [j]. Guangdong electric power, 2011, 24 (6): 47-49.

[6] Li Xiaoming. Discussion on a new method of transmission line bird damage control [j]. Scientific and technical information, 2011 (21): 365-365.

[7] Xiaowei. Strategy on attracting birds in the field of transmission line bird damage control [j]. 
Heilongjiang science and technology information, 2016 (33).

[8] white wide sea. Transmission line bird damage control measures and strategies [C]//national seminar on technology of overhead transmission lines. 2013.

[9] Wang Shaohua, self-improvement. To bird pest accident of overhead transmission line and its preventive technical measures [j]. High voltage apparatus, 2011, 47 (2): 61-67. 